\title{
A better design of the toll plaza on the highway
}

\author{
Shujian Tang \\ School of North China Electric Power University, Beijing 100000,China \\ 1490424785@qq.com
}

\begin{abstract}
Keywords: Arch-Shaped Toll Plaza, a Better Design, Cost, Comparison
\end{abstract}
\begin{abstract}
This paper is aimed to figure out a better design of the toll plaza on the highway, considering the economic reason in addition, to relieve more and more serious congestion at the entrance and exit. We break the traditional thinking and design an arch-shaped toll plaza which consists of two layers (the arch and the ground) with tollbooths on both. Nagel-Schreckenberg Algorithm is applied to determine the number of tollbooths, that is, 4 tollbooths ( 2 on each layer) for a four-lane highway. It is also used to develop a conventional toll plaza with 4 booths for comparison. We calculate the construction and land costs of two designs, and the new one saves $750 \mathrm{~m} 2$ land area and 269,200\$ land cost. And even in heavy traffic the queueing time and length are tolerable. Furthermore, we discuss about the accident prevention and how the new design will change for the increasing of autonomous vehicles. It turns out that the new plaza can flexibly adapt to more autonomous vehicles by increasing ETC booths for their special use. And because drivers don't need to change the lane when passing through the plaza, accident can be significantly prevented. At last, we draw the conclusion that our new design shows great advantages in various aspects and is practicable for the toll plaza construction.
\end{abstract}

\section{Introduction}

Nowadays, almost all toll plazas on the highways, such as barrier tolls, are simply constructed on one layer. However this kind of plaza has a paradox. If the tollbooths are too many, congestion will increases upon departure from the toll plaza normally. On the contrary, if the number of tollbooths is too small, congestion builds at the entry because of the service time. So a good design is needed to improve these problems significantly.

Inspired by the framework and the function of the overpass, we try to design an arch-shaped plaza, which can make good use of land resources and cut down the construction cost.

\section{New Design--Arch-Shaped Toll Plaza}

The sketchers of the plaza are shown below:
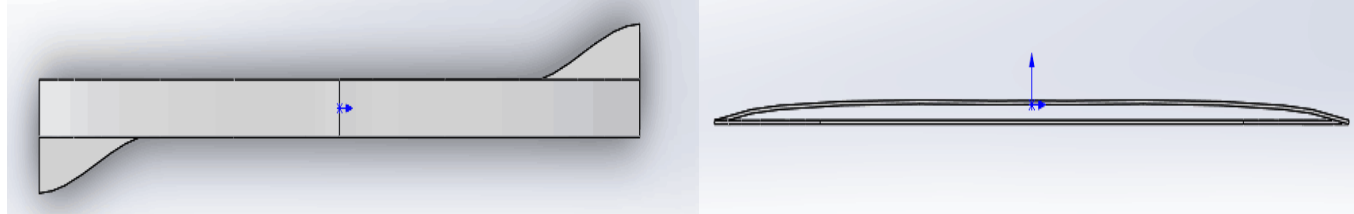

Figure 1. The sketchers of the new plaza

As is demonstrated in Figure 5, our new plaza consists of two layers(the arch and the ground)with tollbooths on both. Considering congestion alleviation and good use of the land resources, we have a primary assumption about the toll booths division:

Assume there are $\mathrm{N}$ toll booths. When $\mathrm{N}$ is odd, we set $\frac{\mathrm{N}-1}{2}$ booths on the upper layer and $\frac{\mathrm{N}+1}{2}$ on the lower layer(for the cost of upper layer is much higher); when $\mathrm{N}$ is even, we set $\frac{\mathrm{N}}{2}$ booths on each layer. The arc areas at the entry and the exit are designed to guarantee that the cars travel the same distance via the upper and the lower layer when passing through the plaza. 
Here we let $\mathrm{N}=4$, and that means 2 booths on each layer. And this is under the assumption of a 4lane highway. With one lane being $3.75 \mathrm{~m}$ wide, the width of the plaza is $15 \mathrm{~m}$ and the length is $300 \mathrm{~m}$, which is noted in Figure 6.

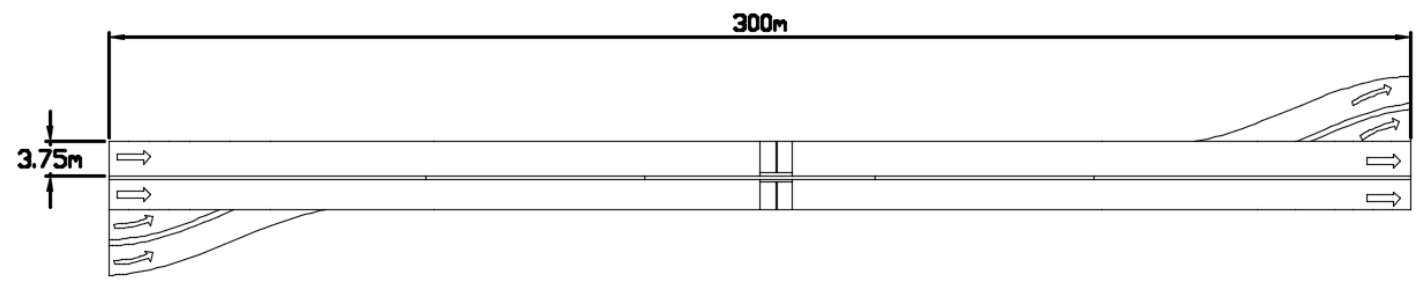

Figure 2. The sizes of the new design

And the merging pattern is illustrated in Figure 3:
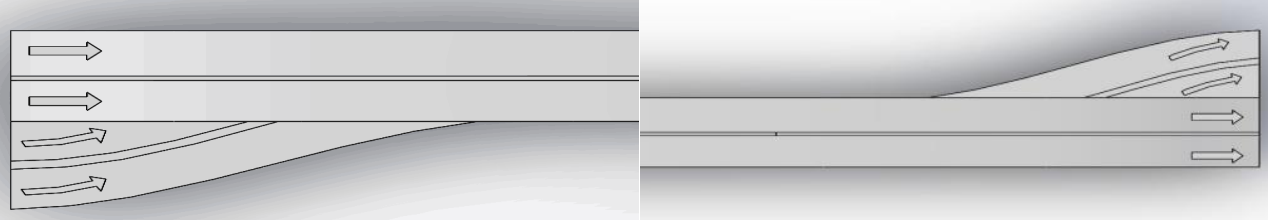

Figure 3. Merging pattern

At the fan-out area of the plaza, vehicles on the two left lanes go up to the arch and pass through the tollbooths on the upper, while vehicles on the two right lanes go through under the arch and pass through the booths on the lower layer. At the fan-in area, vehicles on the upper layer go down from the arch and straightly enter the two right lanes at the fan-in area, while vehicles on the lower layer ought to fan in to the highway via the two left lanes.

Under this circumstance, congestion can be relieved and even prevented, for every vehicle can easily find the specific lane to enter and depart from the plaza, which brings great convenience to the drivers and makes the work of tollbooths more efficient.

\section{Comparison of Area and Cost}

compare the financial practicability of the two designs, we estimate the area and cost of their construction, which may be a little simple but enough to mathematically illustrate the differences between them.

Length of the plaza: $\mathrm{L}_{1}=300 \mathrm{~m}$ (according to Figure)

Average building cost for 1 mile of the highway: $1=10710000 \$ / m i l e($ assume the average building cost for the arch is 1.3 times of $\mathrm{p}$ )

Average land price for $1 \mathrm{~m}^{2}$ of the highway: $\mathrm{p} 2=358.898 \$ / \mathrm{m}^{2}$ (referring to some information on the Internet)

The total area of the new plaza:

$\mathrm{S}_{1}=7.5 \cdot \mathrm{L}_{1}+7.5 \cdot 50=2.625 \times 10^{3} \mathrm{~m}^{2}$

The total area of the conventional plaza:

$\mathrm{S}_{2}=(7.5 \times 2+7.5) \frac{\mathrm{L}_{1}}{2}=3.375 \times 10^{3} \mathrm{~m}^{2}$

The difference between two total areas:

$\Delta \mathrm{S}=\mathrm{S}_{2}-\mathrm{S}_{1}=750 \mathrm{~m}^{2}$

The total building cost of the new plaza:

$\operatorname{sum}_{1}=\frac{\mathrm{L}_{1} \times 10710000 \times 2.3}{2 \times 1600}=2.309 \times 10^{6} \$$

The total building cost of the conventional plaza:

$\operatorname{sum}_{2}=\mathrm{L}_{1} \cdot \frac{10710000}{1600}=2.008 \times 10^{6} \$$ 
The difference between two total building costs:

$\Delta \operatorname{sum}_{1}=\mathrm{sum}_{2}-\mathrm{sum}_{1}=3.012 \times 10^{5} \$$

The land cost that the new design saved:

$\Delta \operatorname{sum}_{2}=\mathrm{p}_{2} \cdot \Delta \mathrm{S}=2.692 \times 10^{5} \$$

\section{Summary}

According to the results above, it is very clear that the new design needs less land area, thus saving the land resources and cost. Although it calls for a little more money on construction because of the expensive price for arch building, taking the saving cost into consideration, the total cost is not much higher than the conventional one.

\section{References}

[1]. Wu Wanyang, Rong Jian, Zhang Zhiyong. Study on Accelation Model of Starting Vehicles in Free Flow. JOURNAL OF HIGHWAY AND TRANSPORTATION RESEARCH AND DEVELOPMENT. Vol.20(2003)No.3,p.144-146

[2]. Chen He: The study of Capacity of Expressway (Master Of Science, Being University of Technology, China 2002).p.4

[3]. Dai Guozhong, Yang Guang, Yang Feng, Xie Haiming. Study on Toll Plaza Capacity Design Method. JOURNAL OF HIGHWAY AND TRANSPORTATION RESEARCH AND DEVELOPMENT. Vol.20(2003)Sup.1,p.96-100.

[4]. .Information on: http://www.dot.state.fl.us/planning/policy/costs/costs-D7.pdf 